\title{
Determination of nutrient salts by automatic methods both in seawater and brackish water: the phosphate blank
}

\author{
X.A. Alvarez-Salgado, F. Fraga and F.F. Pérez \\ Instituto de Investigacións Mariñas (CS1C), Eduardo Cabello 6, 36208 Vigo, Spain
}

Correspondence to: X.A. Alvarez-Salgado, Instituto de Investigacións Mariñas (CSIC), Eduardo Cabello 6, 36208 Vigo, Spain.

\begin{abstract}
Alvarez-Salgado, X.A., Fraga, F. and Pérez, F.F., 1992. Determination of nutrient salts by automatic methods both in seawater and brackish water: the phosphate blank. Mar. Chem., 39: 311-319.

The main inconvenience in determining nutrients in seawater by automatic methods is simply solved: the preparation of a suitable blank which corrects the effect of the refractive index change on the recorded signal. Two procedures are proposed, one physical (a simple equation to estimate the effect) and the other chemical (removal of the dissolved phosphorus with ferric hydroxide).
\end{abstract}

\section{INTRODUCTION}

The colorimetric determination of nutrient salts in seawater by automatic methods with the Technicon AA II (Technicon Instruments, Tarrytown, NY) shows a general systematic tendency to give greater absorbances than those obtained by manual procedures. This phenomenon, already described in the literature (Atlas et al., 1971; Treguer and Le Corre, 1975) occurs because variations in the refractive index when blown glass flowcells are used provoke light dispersion which is converted into an increase in the signal recorded (Froelich and Pilson, 1978). This effect is not produced in a conventional colorimeter that has cells with perfectly fiat polished walls. 
To solve this problem the blank, zero-nutrient seawater, which is compared with the low-nutrient seawater (LNSW) in which the standards are prepared, must have the same refractive index as the LNSW. For this purpose, a solution can be used which contains $35 \mathrm{~g}$ of sodium chloride calcined at $600^{\circ} \mathrm{C}$ in 11 of Milli-Q water. During calcination, the nitrate, ammonium, carbon and organic nitrogen are totally eliminated. On the other hand, silicate is converted into non-reactive forms, thus giving a blank of salinity 35 PSU (Practical Salinity 1978), adequate for the analysis of these nutrients, but not for phosphate. Even using the purest sodium chloride, the phosphate content is very high, to the point where the phosphate concentration of the blank exceeds that of LNSW. In this study, two simple procedures, both suitable for shipboard use, are described to resolve the uncertainty which arises in phosphate determination in seawater as a result of the lack of a satisfactory blank.

\section{MATERIALS AND METHODS}

Determination of phosphate in seawater

This was carried out using the automated method described by Grasshoff et al. (1983), with slight modifications. Thus, to avoid possible contamination when amonium is determined simultaneously, ammonium molybdate was replaced by sodium molybdate. This change makes necessary the increase in the quantity of sulphuric acid in the molybdate reagent so the final $\mathrm{pH}$ of the reaction is lower than one. Also, as a surfactant, Levor V was used instead of Levor IV, which is not recommended by Kirkwood et al. (1991). This is because of the precipitation problems that the latter gives rise to in samples of high salinity, which lead to an absorbance increase with respect to the manual methods (Loder and Gilbert, 1977; Grasshoff et al., 1983). The reproducibility is $\pm 0.01 \mu \mathrm{mol}-\mathrm{Pkg}^{-1}$ in the $0-1 \mu \mathrm{mol}$ range.

\section{Reagents}

The washing water was deionized water. The molybdate reagent was sodium molybdate dihydrate p.a. $12.35 \mathrm{~g}$, concentrated sulphuric acid $91.5 \mathrm{ml}$, potassium antimony tartrate p.a. $0.5 \mathrm{~g}$, distilled water $908.5 \mathrm{ml}$. The ascorbic acid reagent was ascorbic acid $6.0 \mathrm{~g}$, Levor V 1 ml, distilled water 999 ml. The manifold is illustrated in Fig. 1. 
Refractive index correction procedure

To determine the signal increase caused by the change in the refractive index on sending seawater instead of fresh water through the colorimeter flowcell, reagents were prepared in which sodium molybdate or ascorbic acid were replaced by similar substances which do not give a colour reaction, but contribute to that change. The method also allowed us to quantify the degree of contamination of the reagents used. Reagents A and B were prepared as substitutes for the molybdate and the ascorbic reagent respectively. Reagent A was anhydrous sodium sulphate $10.51 \mathrm{~g}$, concentrated sulphuric acid $91.5 \mathrm{ml}$, potassium antimony tartrate p.a. $0.5 \mathrm{~g}$, distilled water $908.5 \mathrm{ml}$. Reagent B was Levor V $1 \mathrm{ml}$, distilled water $999 \mathrm{ml}$.

The experiments are carried out in two stages (Fig. 2). In the first stage, one of the reagents is replaced by its corresponding substitute so that no colour reaction takes place. In the second stage, both reagents are used and, consequently, the reaction occurs.

Initially, in the first stage two possible 'pairs of reagents' can be established: molybdate reagent-reagent $\mathrm{B}$ and reagent A-ascorbic reagent. However, the molybdate reagentreagent $\mathrm{B}$ was rejected on observing that Levor $\mathrm{V}$ is a reducing agent and provokes the colour reaction.

A base-line with distilled water was therefore made for the pair reagent A-ascorbic reagent. On analysing the LNSW in which standards were prepared, an increase in the absorbance signal was observed, and, as there was no colour reaction, the change produced is attributed to the refractive index variation on changing from fresh water to seawater.

On replacing reagent A with the molybdate reagent, i.e. using the molybdate reagentascorbic reagent pair, the colour reaction takes place, showing an increase in absorbance whose magnitude is proportional to the phosphate present in the reagents. Standards of approximately $1 \mu$ mol-P kg-1 prepared in deionized water gave signal $P$, and in seawater $P_{\mathrm{sw}}$. 
Mathematically, taking the base-line with deionized water as zero absorbance, the signal registered in the colorimeter $H_{\mathrm{sw}}$ on analysing the LNSW is due to the phosphate concentration in the sample $M$ and in the reagents $R_{\mathrm{sw}}$, and the absorbance caused by the change in the refractive index on switching from fresh water to seawater $I$

$H_{\mathrm{sw}}=M+R_{\mathrm{sw}}+I$

It should be noted that the absorbance related to the phosphate in the reagents is not $R$ but $R_{\mathrm{sw}}$ because of the effect of the change in ionic strength on switching from fresh water to seawater. Thus

$\frac{\mathrm{R}_{\mathrm{SW}}}{\mathrm{R}}=\frac{\mathrm{P}_{\mathrm{SW}}}{\mathrm{P}}=\mathrm{k}$

and

$\frac{\mathrm{M}}{\mathrm{P}_{\mathrm{sw}}}=\frac{[\mathrm{M}]}{[\mathrm{P}]}$

where $[\mathrm{P}]$ is the $\mathrm{KH}_{2} \mathrm{PO}_{4}$ concentration (in $\mu$ mol- $\mathrm{P} \mathrm{kg}^{-1}$ ) of the standard prepared both in deionized water and LNSW.

Substituting (2) and (3) in (1) and reorganizing, we have

$[\mathrm{M}]=\left(\mathrm{H}_{\mathrm{sw}}-\mathrm{I}-\mathrm{R} \cdot \mathrm{k}\right) \cdot \frac{[\mathrm{P}]}{\mathrm{P}_{\mathrm{sw}}}$

which allows us to calculate the phosphate concentration in the LNSW in which the primary standards are diluted.

In our case, for a standard of $1.013 \mu \mathrm{mol}-\mathrm{P} \mathrm{kg}^{-1}$, setting $P_{\mathrm{sw}}$ to 1000 units, with a standard deviation of \pm 3 , the result was $I=59 \pm 1, R=15 \pm 1$ and $H_{\mathrm{sw}}=257 \pm 3$ units. The $k$ value obtained was $1.024 \pm 0.005$. Substituting these values in eqn. (4), the phosphate concentration in the LNSW used (previously aged and filtered to $0.45 \mathrm{pm}$ ) was estimated at $0.185 \pm 0.005 \mu \mathrm{mol}-\mathrm{Pkg}^{-1}$.

The value of $I$ will remain constant as long as neither the standard calibration set (STD $\mathrm{CAL}$ ) nor the orientation of the flowcell are altered, $k$ will remain unchanged if the method is not modified. However, $H_{\mathrm{sw}}, R$ and $P_{\mathrm{sw}}$ must be determined every time the LNSW or reagents are changed. With this method we can find the phosphate concentration of any sample: 


$$
\begin{aligned}
& {[X]=\left(X^{\prime}-H_{s w}\right) \cdot \frac{[P]}{P_{s w}}+[M]} \\
& =[X-I-(k-1) \cdot R] \cdot \frac{[P]}{P_{s w}}
\end{aligned}
$$

$X^{\prime}$ is the signal caused by the sample and $X=X^{\prime}-R$ (Fig. 2).

Equation (5) is valid provided that the constancy of $I$ and $\mathrm{k}$ is not compromised, and this is so as long as there are no marked salinity fluctuations, $S=35 \pm 3$ PSU being the usual range in the open ocean. However, in estuarine areas-where the salinity can reach very low values-neither $I$ nor $k$ will remain constant. Taking the salinity of the seawater in which standards are prepared as reference $\left(S_{\mathrm{ST}}\right)$ and assuming a linear variation model of these parameters with salinity,

$$
[\mathrm{X}]=\frac{X-[I+(k-1) \cdot R] \cdot \frac{S}{S_{S T}}}{1+(k-1) \cdot \frac{S}{S_{S T}}} \cdot k \cdot \frac{[P]}{P_{S W}}
$$

where $S$ is the salinity of the sample.

Phosphate elimination with ferric chloride

If the phosphate present in seawater used to prepare standards is removed, we will have a suitable blank for the analysis of this nutrient. The phosphate ion, because of the insolubility of the salts it forms with certain cations, interferes in the analysis and must therefore be eliminated. Among the diverse methods proposed is the use of ferric chloride (Burriel et al., 1983). The addition of ferric chloride to seawater leads to the formation of ferric hydroxide, a colloid, which in spite of being very insoluble, as a result of its lyophobic character (Bermejo, 1981), tends to remain in stable suspension for long periods of time. Rapid coagulation of the colloid can be effected by boiling because thermal agitation helps the collision and union of the colloid particles. At the same time, the coprecipitation of the adsorbed phosphate will also take place.

In this study we have verified the effectiveness of this procedure. Various quantities (see Table 1) of $\mathrm{FeC}_{3} \cdot 6 \mathrm{H}_{2} 0$ and $\mathrm{Na}_{2} \mathrm{CO}_{3}$ were added to four aliquots $\left(\mathrm{M}_{1}, \mathrm{M}_{2}, \mathrm{M}_{3}\right.$ and $\left.\mathrm{M}_{4}\right)$ of the same LNSW analysed with the physical method $\left(0.185 \mu \mathrm{mol}-\mathrm{P} \mathrm{kg}^{-1}\right)$. These 
were heated to boiling and the mass lost was made up to the original weight with distilled water. They were then left to settle for $24 \mathrm{~h}$ and finally the precipitate formed was removed by filtration.

This process was repeated with four aliquots $\left(\mathrm{P}_{1}, \mathrm{P}_{2}, \mathrm{P}_{3}\right.$ and $\left.\mathrm{P}_{4}\right)$ for the LNSW to which the standard $\mathrm{KH}_{2} \mathrm{PO}_{4}$ had previously been added (Table 1).

The seawater blank prepared by this method becomes saturated with Fe(III). To verify that this does not affect the analytical reaction, a quantity of perfectly known standard was added to the two aliquots in each of the LNSW samples treated, and the expected value was compared with that obtained experimentally (Table 2).

Chemical method on board

The simplest way to obtain a suitable phosphate-free blank consists of taking an aliquot of the same LNSW in which the standards are going to be prepared and adding to it about $1 \mathrm{ml}$ of a $70 \%$ solution of $\mathrm{FeC1}_{3} \cdot 6 \mathrm{H}_{2} 0$ then $10 \mathrm{ml}$ of a $4 \%$ solution of $\mathrm{Na}_{2} \mathrm{CO}_{3}$ per litre of seawater. This is left to settle for several days until it precipitates (if it is heated to boiling the process is accelerated). Finally, either a part of the supernatant free of precipitate is taken, or the aliquot is filtered through paper, to give a phosphate-free blank.

\section{DISCUSSION}

Refractive index correction procedure

Atlas et al. (1971) working with the AutoAnalyser Technicon AAI were the first to become aware of the problem dealt with here, and quantified it for nitrate, silicate (negligible) and phosphate $(0.02 \mu \mathrm{M})$. Their experiments showed that the effect was more marked with the AA II model. However, they did not give experimental details.

Later, Treguer and Le Corre (1975) proposed the following method to quantify what they called 'turbidity'. They made the base-line without colour reaction by replacing the ammonium molybdate and ascorbic acid in their respective reagents with sulphuric acid 
and distilled water respectively. For seawater with salinity of 35 PSU and filtered through $0.45 \mu \mathrm{m}$, they obtained an $I$ equivalent to $0.12 \mu \mathrm{M}-\mathrm{P}$, a quantity which they subtracted from all the samples. However, as indicated above, this 'concentration' is different for each flowcell and depends on its orientation and on the STD CAL. In contrast, the method proposed here has the advantage that, by replacing only the molybdate reagent with a similar compound, a signal for the refractive index change is obtained that is closer to the signal actually produced in samples. Furthermore, the phosphate in the reagents is taken into account.

Froelich and Pilson (1978) dealt with this problem in great detail, but the solutions they proposed are not suitable for application on board ship. They constructed a refractive index correction graph and obtained a systematic error of about $0.2 \mu \mathrm{M}-\mathrm{P}$ at salinity 35 PSU with the Technicon method for phosphate determination.

Phosphate elimination with ferric chloride

It has been demonstrated that ferric chloride is effective in the elimination of phosphate from seawater, and also that the presence of dissolved Fe(III) does not interfere with the analytical reaction. This means that the colorimetric signal obtained on analysis of this blank includes not only the effect of the refractive index variation, but also of the phosphate in the reagents. Sodium carbonate is added to restore the seawater's natural $\mathrm{pH}$.

Newell (1962) and Novoselov et al. (1976) have already proposed procedures of this type, adsorption by transition metal hydroxides, to remove the phosphate dissolved in seawater. The former used aluminium hydroxide to remove all the dissolved phosphorus (organic and inorganic) and later to analyse it in the precipitate. The latter used zirconyl hydroxide, which is capable also of fixing silicate.

The two procedures proposed here, correction of the effect of the refractive index change (physical) and preparation of a reference phosphate-free seawater (chemical), are consistent within the reproducibility of the method. This guarantees the validity of the model for estimation of the refractive index and the effectiveness of the phosphate elimination by removal with Fe(III). They are suitable for shipboard use. In the physical 
procedure, once $k$ is calculated, it will remain constant provided that the method is not modified (1.024 \pm 0.005 in our case). It is sufficient to determine $I$ each time the LNSW is changed or the orientation of the flowcell or the STD CAL is modified (these last two possibilities are very unlikely on board ship) and $R$ every time the reagents are changed. In any case, the problem reduces to that of carrying out, in part or in full, the process described in Fig. 2 before starting a group of analyses. This takes only half an hour and it is only necessary to prepare one additional reagent, reagent $\mathrm{A}$. In the simpler chemical method, following the procedure above, a phosphate-free blank is prepared from the LNSW.

\section{ACKNOWLEDGEMENTS}

Support for this work came from CICYT (MAR88-0245 project) and Conselleria de Pesca de la Xunta de Galicia. We thank Dr. M. Zdanowsky and Félix and Josefa Fernández for their help in the translation of a Russian paper, and R. Penin in the preparation of figures. We also thank three anonymous reviewers for their valuable suggestions and comments on an earlier version of this paper.

\section{REFERENCES}

Atlas, E.L., Gordon, L.I., Hager, S.W. and Park, P.K., 1971. A practical manual for use of the Technicon AutoAnalyzer in seawater nutrient analyses (revised). Department of Oceanography, School of Science, Oregon State University, Tech. Rep. 215, corvalais 48 pp.

Bermejo, F., 1981. Química Analítica General, Cuantitativa e Instrumental, I, 6th edn. Dossat, Madrid, 871 pp.

Burriel, F. Lucena, F., Arribas, S. and Hernández, J., 1983. Química Analítica Cualitativa, 11th edn. Paraninfo, Madrid, 1050 pp.

Froelich, P.N. and Pilson, M.E.Q., 1978. Systematic absorbance errors with Technicon AutoAnalyzer II colorimeters. Water Res., 12: 599-603.

Grasshoff, K., Ehrhardt, M. and Kremling, K. (Editors), 1983. Methods of Seawater Analysis, $2^{\text {nd }}$ edn. Verlag Chemie, Weinheim, 419 pp. 
Kirkwood, D., Aminot, A. and Perttil/i, M., 1991. Fourth intercomparison exercise for nutrients in seawater. Cooperative Research Report No. 174. ICES, Copenhagen, 83 pp.

Loder, T.C. and Gilbert, P.M., 1977. Blank and salinity corrections for automated nutrients analysis of estuarine and seawaters. UNH Sea Grant UNH-5G-JR-101 and WHOI Contribution 3897, 29 pp.

Newell, B., 1962. Sorption of dissolved phosphorus from sea-water by means of aluminium hydroxide. Nature, 195: 72-73.

Novoselov, A.A., Sheremetieva, A.I. and Danilenko, A.F., 1976. A method for a simultaneous obtaining of silicon-free and phosphate-free sea water aboard ship (in Russian) Oceanology, XVI: 627-629.

Treguer, P. and le Corre, P., 1975. Manuel d'analyse des sels nutritifs dans l'eau de mer (utilisation de l'AutoAnalyzer II Technicon ${ }^{\mathrm{R}}$ ), 2nd edn. Laboratoire D'Océanologie Chimique, Universitè de Bretagne Occidentale, Brest, 110 pp. 
Fig. 1. Manifold for the automatic determination of phosphate. The values in the peristaltic pump are the pumping volumes (in $\mathrm{ml} \mathrm{min}^{-1}$ ).

Fig. 2. Experimental method followed for the refractive index correction. $I$, signal related to refractive index; $R$, phosphate in the reagents; $P$, phosphate in the freshwater standard; $P_{\mathrm{sw}}$, phosphate in the seawater standard; $H_{\mathrm{sw}}$, LNSW signal; $X^{\prime}$, sample signal $\left(X=X^{\prime}-R\right)$.

\section{TABLE 1}

Effectiveness of the phosphate elimination in seawater by treatment with $\mathrm{Fe}(\mathrm{llI})$

\section{TABLE 2}

Verification of non-interference between Fe(lll) and the analytical reaction 
Table 1

\begin{tabular}{lllll}
\hline Sample & $\begin{array}{l}\text { Fe(III) added } \\
\left.(\mu \mathrm{mol} \mathrm{kg})^{-1}\right)\end{array}$ & $\begin{array}{l}\mathrm{CO}^{2} \text { added } \\
\left.(\mu \mathrm{mol} \mathrm{kg})^{-1}\right)\end{array}$ & $\begin{array}{l}\text { Initial phosphate } \\
\left.(\mu \mathrm{mol} \mathrm{kg})^{-1}\right)\end{array}$ & $\begin{array}{l}\text { Final phosphate } \\
\left.(\mu \mathrm{mol} \mathrm{kg})^{-1}\right)\end{array}$ \\
\hline $\mathrm{M}_{1}$ & 0.86 & 1.23 & 0.185 & 0.186 \\
$\mathrm{M}_{2}$ & 8.83 & 12.6 & 0.185 & 0.138 \\
$\mathrm{M}_{3}$ & 92.5 & 132 & 0.185 & 0.050 \\
$\mathrm{M}_{4}$ & 886 & 1266 & 0.185 & 0.011 \\
$\mathrm{P}_{1}$ & 1.08 & 1.54 & 1.159 & 1.156 \\
$\mathrm{P}_{2}$ & 10.4 & 14.8 & 1.139 & 0.927 \\
$\mathrm{P}_{3}$ & 103 & 146 & 1.137 & 0.321 \\
$\mathrm{P}_{4}$ & 1010 & 1442 & 1.134 & 0.023 \\
\hline
\end{tabular}

Table 2

\begin{tabular}{llllll}
\hline Sample & $\begin{array}{l}\text { Initial } \\
\text { phosphate } \\
\left.(\mu \mathrm{mol} \mathrm{kg})^{-1}\right)\end{array}$ & $\begin{array}{l}\text { Added } \\
\text { phosphate } \\
\left.(\mu \mathrm{mol} \mathrm{kg})^{-1}\right)\end{array}$ & $\begin{array}{l}\text { Total } \\
\text { phosphate } \\
\left.(\mu \mathrm{mol} \mathrm{kg})^{-1}\right)\end{array}$ & $\begin{array}{l}\text { Measured } \\
\text { phosphate } \\
\left.(\mu \mathrm{mol} \mathrm{kg})^{-1}\right)\end{array}$ & $\begin{array}{l}\text { Error } \\
(\%)\end{array}$ \\
\hline $\mathrm{MP}_{1}$ & 0.185 & 0.994 & 1.179 & 1.184 & 0.4 \\
& 0.185 & 0.880 & 1.065 & 1.057 & -0.8 \\
$\mathrm{MP}_{2}$ & 0.185 & 0.920 & 1.105 & 1.100 & -0.4 \\
& 0.185 & 0.935 & 1.120 & 1.114 & -0.5 \\
$\mathrm{MP}_{3}$ & 0.185 & 0.959 & 1.144 & - & - \\
& 0.185 & 0.966 & 1.151 & 1.145 & -0.5 \\
$\mathrm{MP}_{4}$ & 0.185 & 0.921 & 1.106 & 1.109 & 0.3 \\
& 0.185 & 1.031 & 1.216 & 1.210 & -0.5 \\
\hline
\end{tabular}

